\title{
The analysis of relationship between fear of falls with depression in aged
}

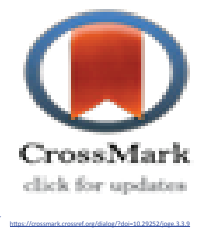

\section{diabetic}

\section{Mohammadi B ${ }^{1}$, *Ilali E.S ${ }^{2}$, Taraghi Z3 , Moosazadeh $\mathrm{M}^{4}$}

1- MSc, Department of Nursing, Nasibeh Nursing and Midwifery Faculty, Mazandaran University of Medical Sciences, Sari, Iran.

2- Diabetes research Center, Mazandaran University of Medical Sciences, Sari, Iran (Corresponding author)

E-mail: paradis2082000@yahoo.com

3- Diabetes research Center, Mazandaran University of Medical Sciences, Sari, Iran.

4- Assistant Professor, Department of Epidemiology, Health Sciences Research Center, Mazandaran University of Medical Sciences, Sari, Iran.

\section{Abstract}

Introduction: Fall is the most common and serious problem that occurs in Aged,which has significant effects on their health and quality of life.The purpose of this study was to determine the relationship between fear of falls and depression in Aged diabetic patients in Amol hospitals.

Method: This is a descriptive - analytic study that was conducted in 2018. The corpus of study involved 191 Aged diabetic patients aged 60 years and over. Sampling method was available. The instrument for data collection was demographic characteristics, FES-I scales, a fifteen-item questionnaire GDS and AMT and ADL. Data analysis was done by using descriptive and inferential tests and was shown via SPSS software.

Results: Most participants (50.3\%) were female. The average age of participants was $70.4 \pm 6.6$ years. Based on the findings, the average of fear of falling was $(25 \pm 8.7)$ and average of depression was $(6.7 \pm 2.1)$. The results of Spearman's correlation coefficient showed a significant positive correlation between fear of falling and depression $(P=0.001, r=0.234)$. So that the fear of falls of the Aged were increased, their depression also increased.

Conclusion: The results of this study showed that there is a significant relationship between the fear of falling and depression in Aged people. So, psychological treatments and exercise should be done to reduce their fear of falling.

Key words: Fear of Fall, Depression, Aged, Diabetes.

Received: 4 December 2018

Accepted: 12 February 2019

\begin{tabular}{|l|l|}
\hline \multicolumn{3}{|c|}{ Access this article online } \\
\hline
\end{tabular}




\title{
بررسى ارتباط ترس از سقوط با افسر دَى در سالمندان ديابتيك: يك مطالعه يِي بينى كننده
}

\author{
بيتا محمدى'، "احترام السادات ايلاليّ، زهره ترقى"، محمود موسى زاده"
}

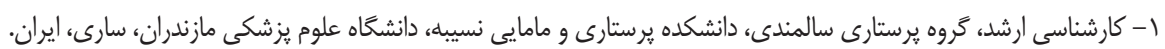

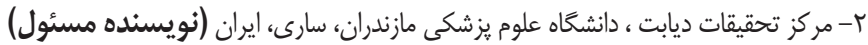

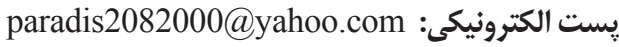

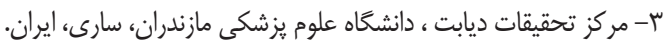

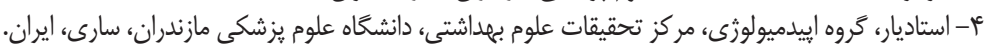

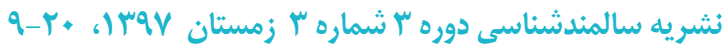

\section{جكيده}

مقدمه: سقوط يكى از شايع ترين و جدى ترين مشكلاتى است كه در دوران سالمندى نمود ييدا مى كند كه اثرات قابل توجهى بر

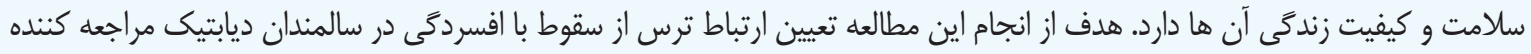

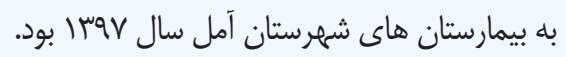

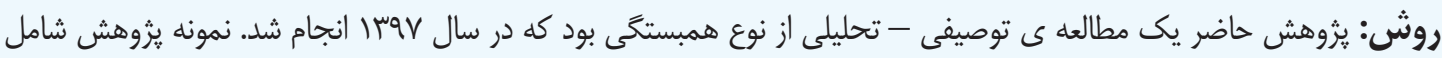

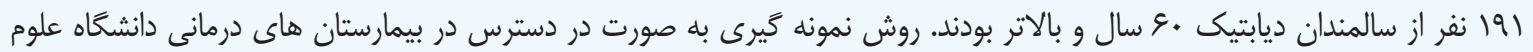

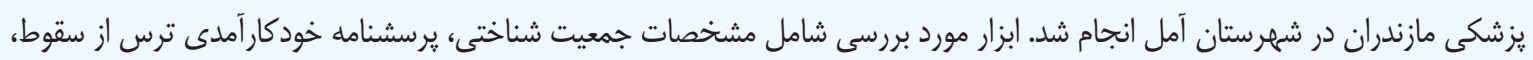

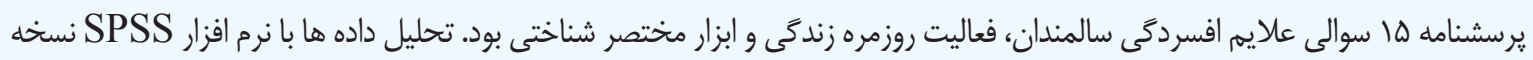

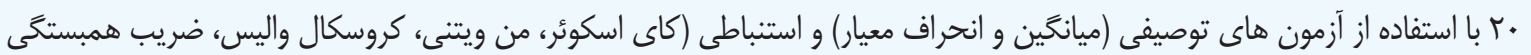
اسبيرمن، ركرسيون خطى، خريب همبستخى يارشيال) انجام شد.

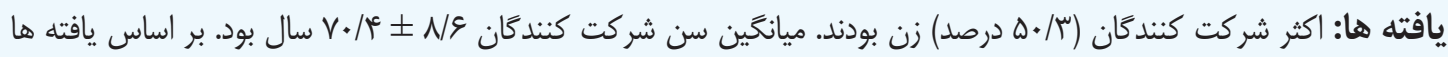

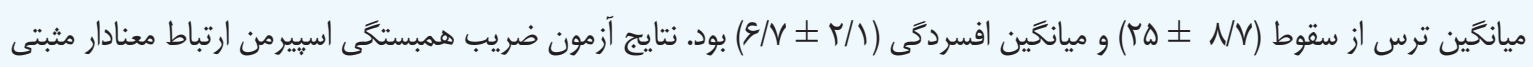

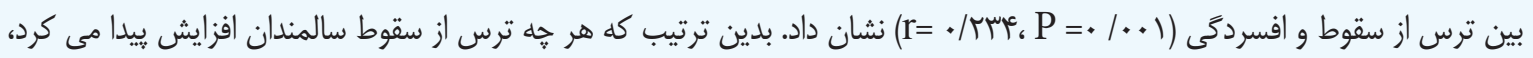
افسردمى آن ها نيز بيشتر مى شد. نتيجه كَيرى: نتايج مطالعه نشان داد كه ارتباط معنى دارى بين ترس از سقان سقوط و افسردمى در سالمندان وجود دارد، لذا مى بايست

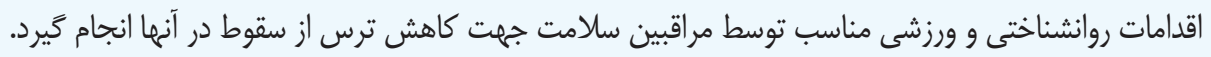
كليد وازه ها: ترس از سقوط، افسردگى، سالمندان، ديابت. 
زمين خوردن فعاليت بدنى شان بدتر مى شود، سيكل معيوبى را تجربه مى كنند كه منجر به افزايش ميزان بسترى شدن و مركى مى شود (أl). ترس از سقوط ميتواند به يك بيمارى ناتوان كننده تبديل شود. جون ترس از سقوط ميتواند با ييامدهاى منفى از جمله كاهش انجام كارهاى روزمره زندگى (ه) (1)، كاهش فعاليت فيزيكى (19)، درك وضعيت سلامت جسمانى پإيينتر (IV) و افزايش زمان بسترى شدن همراه باشد (19،19). از طرف ديخر با افزايش سن احتمال وقوع بيمارى هاى مزمن نيز بيشتر مى شود (·r). ديابت

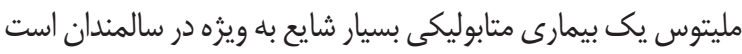

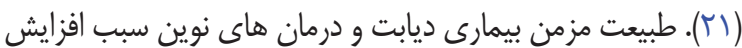
طول عمر بيماران ديابتى شده (Tr). عوارض آن سبب افت عملكرد اين بيماران مى شود. افت عملكرد ناشى از بيمارى هاى مزمن مى تواند سقوط را كه شايعترين علت صدمه در سالمندان است، افزايش ستردان دهد (T) ديابت يك عامل خطر عمده براى سقوط محسوب مى

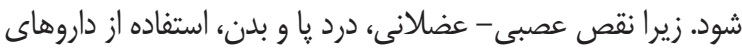
روان تردان، مصرف داروهاى متعدد و عملكرد ضعيف قدم برداشتن، كاهش عملكرد شناختى و نوروياتى محيطى از جمله دلايلى هستند كه سقوط در سالمندان ديابتى را افزايش مى دهند. نوروياتى محيطى لهى به عنوان شايعترين عارضه در حدود نيمى از افراد مبتلا به ديابت است دها داست كه سبب اختلال حسى، حركتى در قسمت يايين بدن و پاهاو اختلال اتونوميك مى شود. كه اين نقص ها باعث تغيير در عملكرد قدم زدن فرد و تعادل مى شود، كه بخصوص در سالمندان مسن و سالخورده احتمال وقوع سقوط را افزايش مى دهد. از طرفى ديابت خود باعث ايجاد آسيب بيشتر به سيستم عصبى مى شود كه خود منجر به

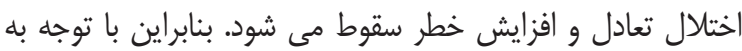

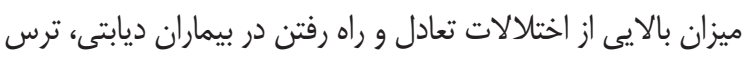

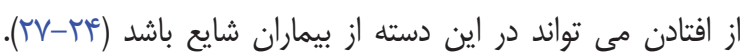
با توجه به اينكه ترس از افتادن يك نشانه مهم روانى و شايع در سالمندان مى باشد ولى به ميزان كمى در بيماران ديابتى مورد بررسى الهى

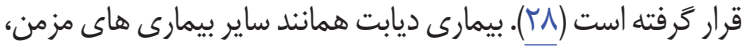
علاوه بر مركَ و مير بالا، مشكلات فردى، مالى و آثار روان يزشكى براى فرد مبتلا به همراه دارد (9r). يكى از واكنش هاى افراد مبتلا

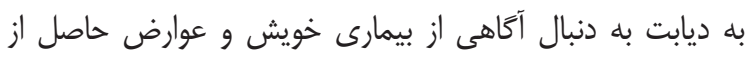

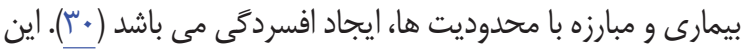
ميزان در مطالعات انجام شده در ايران تا أمه درصد نيز كزارش شدها است (اس). از طرف ديخر در مطالعات مختلف، ارتباط متناقضى بين

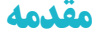

يكى از مهم ترين تغييراتى كه در قرن بيست و يكم در ساختار اجتماعى جوامع به وجود آمده، افزايش شمار جمعيت سالمندان است (1). بر طبق كزارشى از سازمان بهداشت جهانى كه در سال سا •r

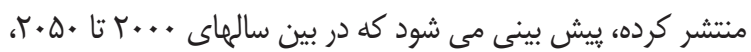
جمعيت افراد •و سال به بالاى جهان دو برابر مى شود؛ به اين صورت كه از ال ادرصد به بr درصد و از ه.\$ ميليون نفر به ب بيليون نفر خواهد رسيد (با). نتايج حاصل از سر شمارى عمومى در كشور ما نشان داده كه روند يير شدن جمعيت در ايران نيز آغاز شده است و بر اساس سر شمارى سال هوسا، در ايران جمعيت بالاى •9 سال

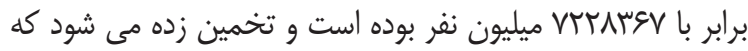

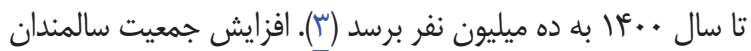

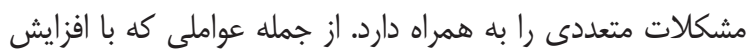
سن، احتمال وقوع آن بيش تر مى شود، سقوط سالمندان است كه عوارض جسمى، روانى، اجتماعى و اقتصادى فراوانى به همراه دارد ('أي ه). سقوط يكى از شايع ترين و جدى ترين مشكلاتى است كه

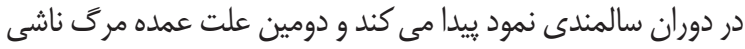
از مصدوميت هاى غير عمدى در جهان است (و). سقوط مى تواند

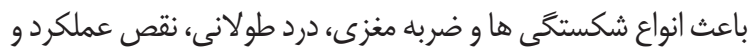
ناتوانى، افزايش وابستگى، يذيرش در خانه هاى سالمندان، افسردگى و ترس از سقوط شود. در بين عوارض روانى سقوط در سالمندان، يديده ترس از سقوط از اهميت ويثه اى برخوردار مى باشد (أ، V، A).

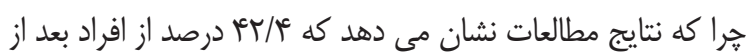
سقوط قادر به برخاستن نيستند. آثار روانى ناشى از سقوط مى تواند به نقص حركتى و كاهش كيفيت زندگى سالمندان منتهى شود (9.، •1). افراد سالمند به دليل ترس از سقوط از انجام يك سرى فعاليتها مانند تهيه غذا يا بياده روى خوددارى مى كنند (؟ا،(1). ترس و وحشت بيش از حد نسبت به سقوط ممكن است سبب عواقب جدى مانند انزوا، كاهش اعتماد به نفس و خودكارآمدى شود كه مى تواند به عنوان مانعى مهم براى فعاليت جسمى باشد. اين در حالى است كه فعاليت جسمى مناسب در دوره سالمندى از عوامل اصلى سالمندى موفق به شمار مى رود (با). بررسى ها نشان مى دهد كه ميزان شيوع و بروز ترس از سقوط در سالمندان آسيايى افزايش يافته و در سالمندان بسترى در بيمارستان يا ساكن خانه هاى سالمندان بيشتر است. ترس از زمين خوردن حتى در بين سالمندانى كه سابقه سقوط

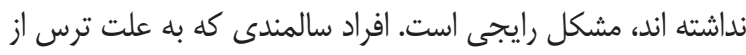


استفاده از نتايج مطالعه Painter و همكاران (T/ • (T) برآورد گرديد

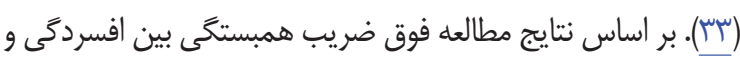

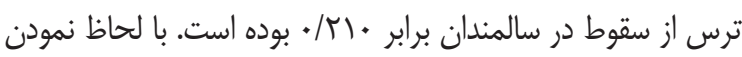

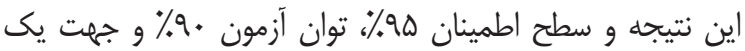

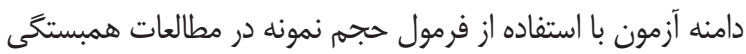
در نرم افزار G-power برابر الوان نفر تعيين كَديد. قبل از انجام يرسشكرى ضمن توضيح هدف از اجراى تحقيق، به سالمندان مورد مطالعه اطمينان داده شد كه اطلاعات يرسشنامه كاملا محرمانه

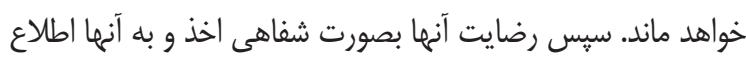

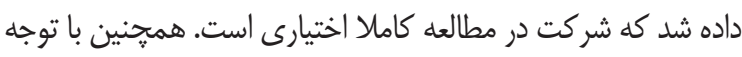

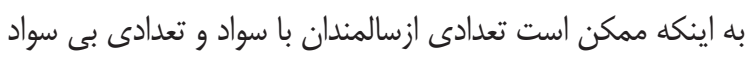

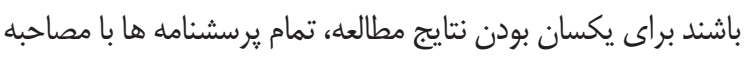
از همه سالمندان توسط محقق تكميل شد. ابزار كرداورى داده ها

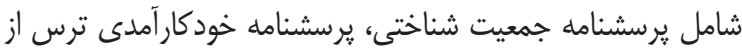
سقوط، يرسشنامه ها سوالى علايم افسردگى سالمندان (فرم كوتاه)،

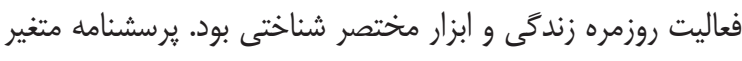

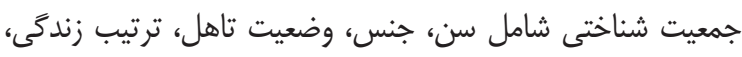

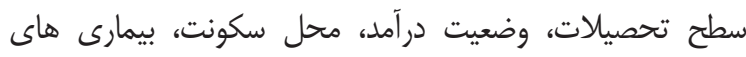

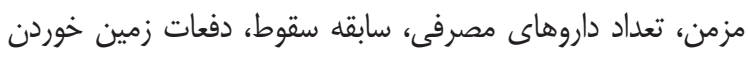

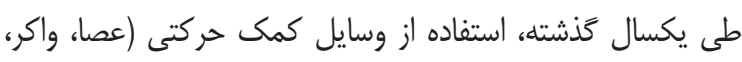

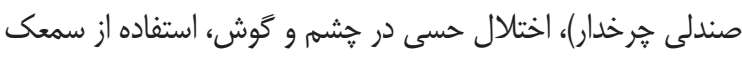
يا عينى بود. يرسشنامه خودكارآمدى ترس از سقوط (خدار) Falls Efficacy Scale- International كه توسط Yardley و همكاران در سال ه •.r ساخته شده است

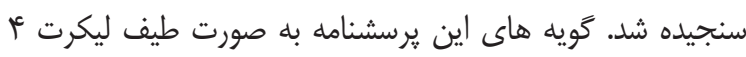

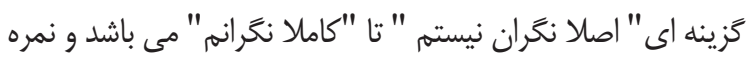

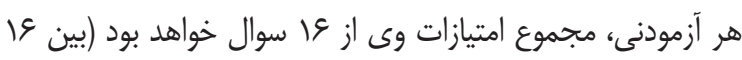

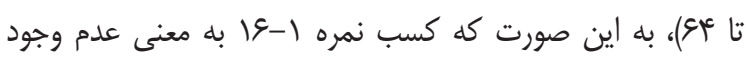

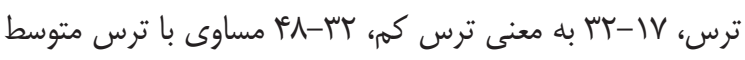

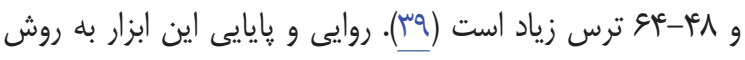

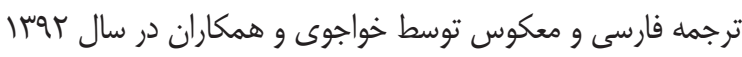
بر روى سبr نفر از سالمندان (بالاى •ع سال) شهر اراى انجام شده

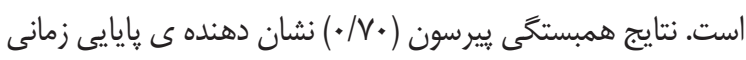

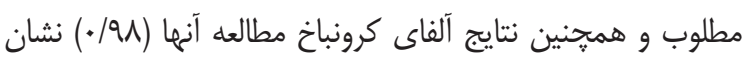

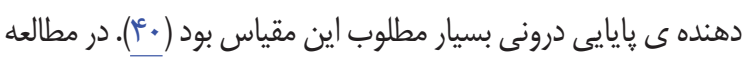

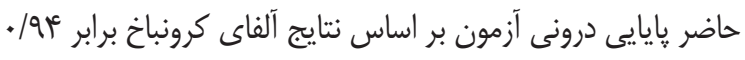

افسردحى و ترس از سقوط گزارش شده است؛ به طورى كه در برخى

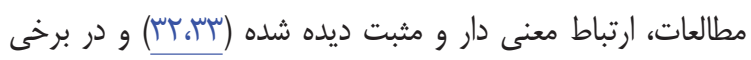

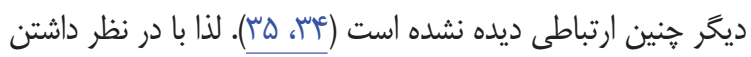

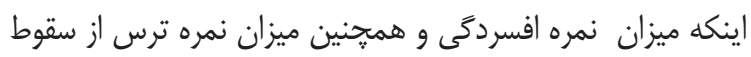

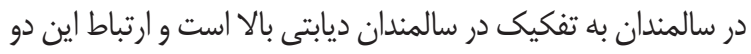
عامل به ميزان كمى در بيماران ديابتى مطالعه شده است (عَّ، (؟).

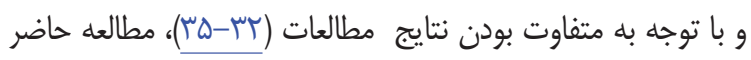

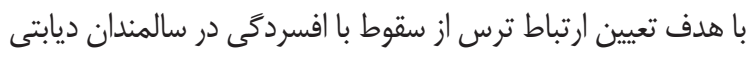
مراجعل كننده به بيمارستان هاى شهرستان آمل طراحى شده است.

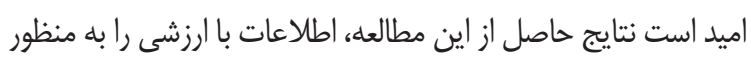
يبشخيرى، طراحى مداخلات و تدابير مراقبتى مناسب در اين زمينه براى ارتقا بيشتر سلامت سالمندان ديابتيك فراهم كند.

\section{ووش مطالعه}

مطالعه حاضر، يك مطالعه همبستخى از نوع توصيفى - تحليلى است كه به صورت مقطعى در سال لوجسا انجام شد.

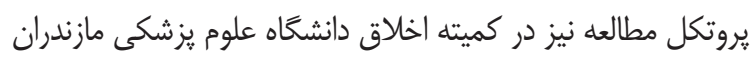

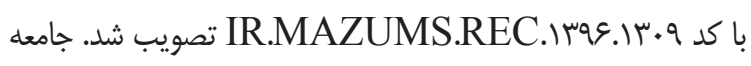
يزوهش مطالعه حاضر را تمامى سالمندان ديابتى •9 سال و بالاتر

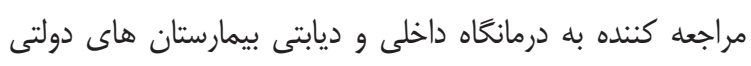

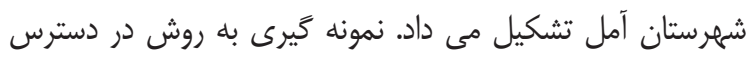

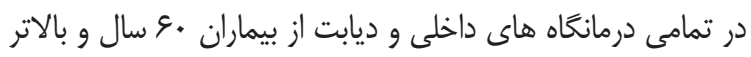
مراجعه كننده انجام شد. معيار ورود شامل: سن •ع سال و و بالاتر، كسب نمره \يا بالاتر در آزمون سلامت روان شناختى (AMT) Abbreviated Mental Test

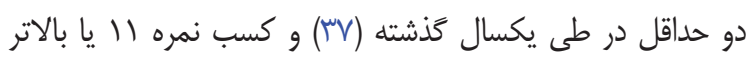

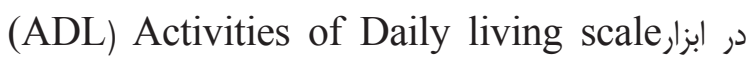
(استفاده كاه به كَاه از عصا يا واكر مانعى ندارد) مى باشد و معيار خروج شامل داشتن هركّونه اختلال عصبى شناخته شده (بيمارى

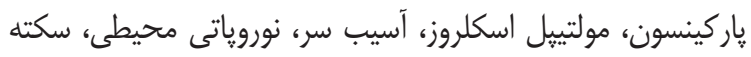

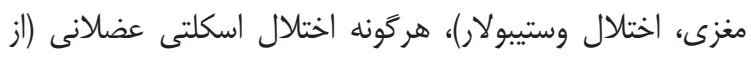
جمله جايخزينى مفصل، قطع عضو يا ارتريت محدود كننده فيزيكى)،

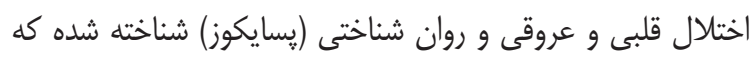
فعاليت هاى روزمره فيزيكى فرد را محدود مى كند (بسا)، وابستخى

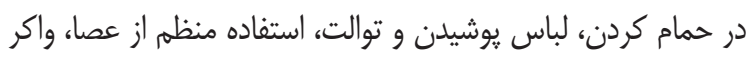

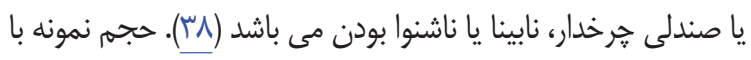


است. در اين ابزار به هر ياسخ صحيح يك امتياز داده مى شود و

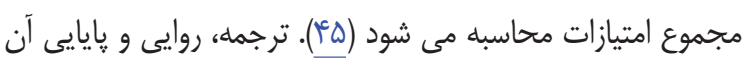

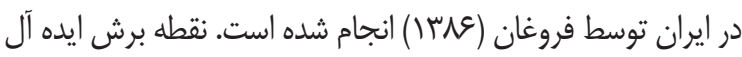

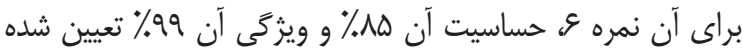

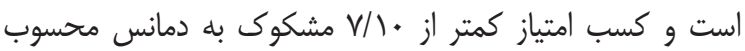

مى شود (ع أ).

تجزيه و تحليل داده ها با نرم افزار SPSS ورثن •r با

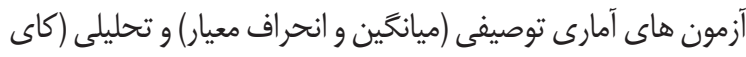
اسكوئر، من ويتنى، كروسكال واليس، ضريب همبستخى اسيبرمن، ركرسيون خطى، ضريب همبستىى هارشيال) انجام شد. نرمال

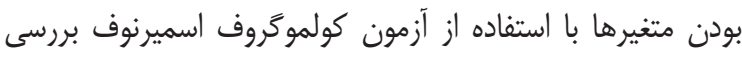
شد. مقايسه متغيرهاى كروه بندى شده با آزمون كاى اسكوئر، مقايسه متغيرهاى كمى با آزمون من ويتنى، كروسكال واليس و

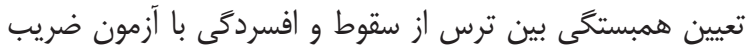
همبستخى اسيبرمن انجام كَرفت. همجنين براى تعيين عوامل مرتبط با افسردگى از ركر سيون خطى استفاده شد. براى حذف اثر متغير هاى

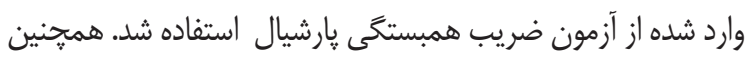

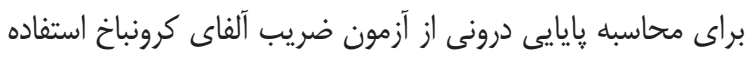

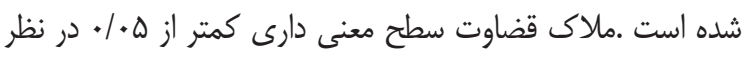

كرفته شده است.

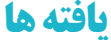

191 سالمند در مطالعه شر كت كردند كه ميانكَين سنى آنها

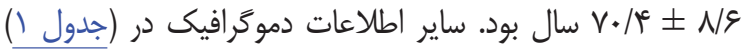

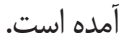

بوده است .كه نشان دهنده پِايايى درونى بسيار خوب اين مقياس

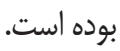
علايم افسردىى با استفاده از مقياس افسردىى سالمندان

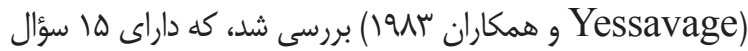
دوَزينهاى (بلى، خير) است. به اين صورت كه كسب نمره ז-ب.

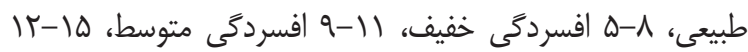
افسردگى شديد است. روايى و پايايى اين يرسشنامه در ايران انجام شده است و نقطه برش \& حساسيت و ويثگى 9/· و سه/· داشته

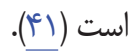

ابزار فعاليت هاى روزمره زندگى توسط Katz (سوال)

طراحى شده است (T) و و اطلاعات مربوط به هفت فعاليت عمده (غذا خوردن، يوشيدن و درآوردن لباس، راه رفتن، انجام دادن كارهاى مربوط به وضعيت ظاهر، حمام كردن، به تخت يا رختخواب رفتن و بيرون آمدن، توالت رفتن) را بصورت سه گزينه اى (مستقل، نيازمند كمك، وابسته) امتياز بندى مى كند. به اين صورت كه كسب نمره

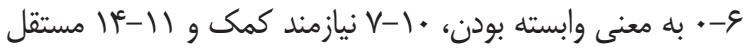

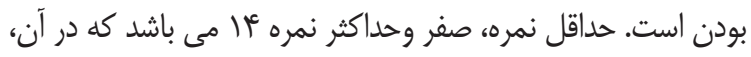
نمرهى بالاتر نشان دهنده ى استقلال بيشتر فرد است. بإيايى ابزار فوق در ايران با آزمون مجدد 9 • توسط حبيبى سولا كزارش شده

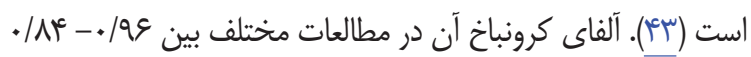

كزارش شده است (ثَأ). جهت بررسى اختلال شناختى از آزمون مختصر شناختى استفاده شد كه توسط Hodkinson (AMT) شده است. اين آزمون يك يرسشنامه •ا سوالى دو گزينه اى است و داراى اعتبار و سرعت بالاى ارزيابى شناختى در بيماران سالخورده

جدول (: توزيع متغيرهاى جمعيت شناختى سالمندان ديابتيك مراجعه كننده به بيمارستان هاى شهرستان آمل سال Vوسا

\begin{tabular}{|c|c|c|c|c|c|c|c|}
\hline درصد & فراوانى & \multicolumn{2}{|c|}{ متغير } & درصد & فراوانى & \multicolumn{2}{|l|}{ متغير } \\
\hline $\begin{array}{l}S V / \mathcal{G} \\
\Delta T / \mathcal{F}\end{array}$ & 91 & روستا & محل سكونت & $\begin{array}{l}\Delta \cdot / r \\
+q / V\end{array}$ & $\begin{array}{l}98 \\
90\end{array}$ & زمن & جنسيت \\
\hline $\begin{array}{l}\varepsilon / \Lambda \\
V Q / \mathcal{C} \\
I V / \Lambda\end{array}$ & 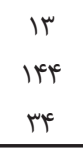 & همراه با همسر & ترتيب زندگى & $\begin{array}{l}99 / 0 \\
r \cdot / 9 \\
r / 9\end{array}$ & $\begin{array}{l}\text { ITV } \\
09 \\
0\end{array}$ & 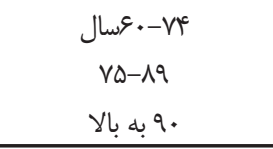 & سن سن \\
\hline $\begin{array}{l}r \Psi / 1 \\
V Q / q\end{array}$ & $\begin{array}{l}\text { is } \\
\text { IfD }\end{array}$ & خير & بيمارى مزمن & $\begin{array}{l}\text { ra } \\
\text { rt }\end{array}$ & $\begin{array}{l}1199 \\
\text { er }\end{array}$ & بدون همسر & وضعيت تاهل \\
\hline $\begin{array}{l}\Delta 1 / \mu \\
r T / q \\
19 / \Lambda\end{array}$ & $\begin{array}{l}91 \\
91 \\
\text { re }\end{array}$ & زيل زيى دييلم & تحصيلات & $\begin{array}{l}r V / T \\
g I / \mu \\
1 / q\end{array}$ & $\begin{array}{l}n \\
n \\
r\end{array}$ & 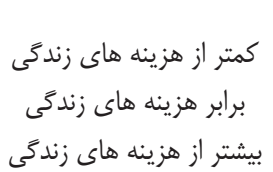 & وضعيت درآمد \\
\hline
\end{tabular}




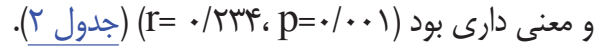
جدول ץ: توزيع شاخص هاى مركزى و يراكندگى ترس از سقوط و افسردگى

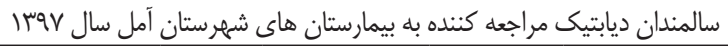

\begin{tabular}{|c|c|c|c|c|}
\hline p-value & $r$ & انحراف معيار & ميانكين & متغير \\
\hline \multirow{2}{*}{$.1 .+1$} & \multirow{2}{*}{. } & $\Lambda / \mathrm{V}$ & ra & ترس از سقوط \\
\hline & & $r / 1$ & $s / \mathrm{V}$ & افسردخى \\
\hline
\end{tabular}

همجنين پِّ از حذف متغيرهاى مخدوشكَر (جنس، وضعيت تاهل، ترتيب زندگى، سطح تحصيلات، بيماريهاى مزمن، تعداد داروهاى مصرفى) رابطه معنى دار مثبتى بين ترس از سقوط و

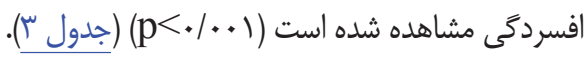
جدول "ج: همبستخى ترس از سقوط و افسردگى يس از حذف متنغير هاى

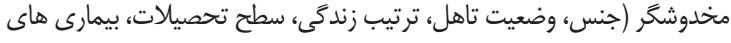

\begin{tabular}{|c|c|c|}
\hline \multicolumn{3}{|c|}{ مزمن، تعداد داروهاى مص } \\
\hline p-value & $\mathrm{r}$ & Partial correlations \\
\hline$<\cdot|.|$. & ./RA9 & ترس از سقوط \\
\hline
\end{tabular}

نتايج تحليل ركرّيون خطى تك متغيره نشان داد ترس از

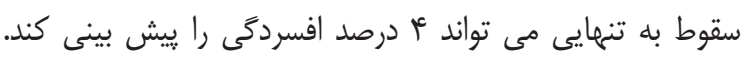

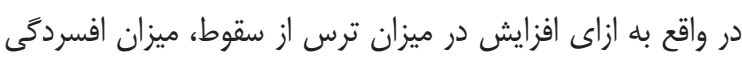

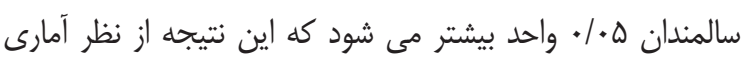

$$
\text { معنى دار مى باشد. (جدول مأ). }
$$

نتايج مطالعه حاكى از اين بود كه Vץ نفر ( (9/4 درصد) ترس

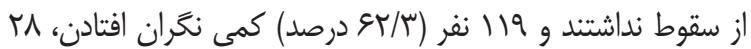

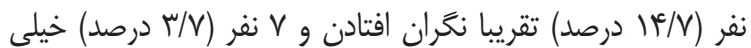
نخران افتادن بودند. نتايج مطالعه نشان داد VY نفر (ا/F/ درصد)

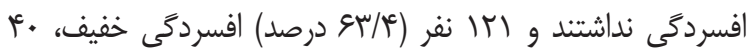

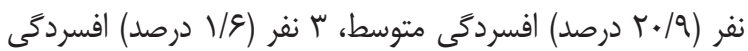
شديد داشتند. ميانكين ترس از سقوط و افسردگى در (جدولى) آمده است. يافته ها نشان داد ترس از سقوط با عواملى همجحون

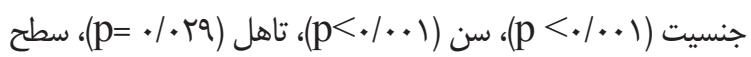
تحصيلات (1.•/

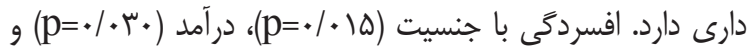

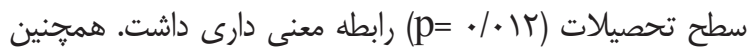
متوسط امتياز ترس از سقوط در سالمندان زن (TV/VIq) بالاتر

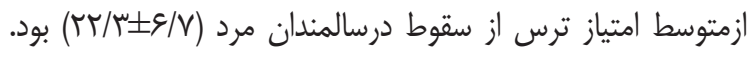
اكثر سالمندان مرد ( / /9 درصد) و اكثر سالمندان زن (ه/ ع درصد) مورد مطالعه ترس از سقوط كم داشتند. متوسط امتياز افسردىى

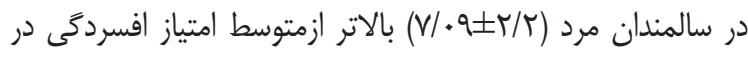

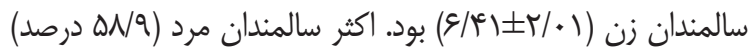
و همجنين اكثر سالمندان زن (9V/V درصد) مورد مطالعه افسردگى خفيف داشتند. از طرفى ترس از سقوط با افسردىى داراى رابطه مثبت

جدول fا: تحليل رگر سيون خطى تكى متغيره عوامل موثر بر افسردگى در سالمندان ديابتيك مراجعه كننده به بيمارستان هاى شهرستان آمل سال Vوسا

\begin{tabular}{|c|c|c|c|c|c|c|c|}
\hline سطح معنى دارى & ضريب بتا & \multicolumn{2}{|c|}{ متغير } & سطح معنى دارى & ضريب بتا & \multicolumn{2}{|c|}{ متغير } \\
\hline $\begin{array}{c}- \\
. / O T \Lambda \\
\end{array}$ & $\begin{array}{c}- \\
-. / 19 \\
\end{array}$ & روستايى & سكونت & $\begin{array}{c}- \\
* * 1 . r q\end{array}$ & $\begin{array}{c}- \\
-\cdot 18 \Lambda \\
\end{array}$ & مرد & جنس \\
\hline.$/ M A T$ & .1 .4 & \multicolumn{2}{|c|}{ سن } & $* \cdot / . r$ & .1 .0 & \multicolumn{2}{|c|}{ ترس از سقوط } \\
\hline $\begin{array}{c}- \\
\cdot / V V^{m} \\
\end{array}$ & $\begin{array}{c}- \\
. / 1 \\
\end{array}$ & خير & سابقه بيمارى & $\begin{array}{c}- \\
.1990 \\
\end{array}$ & $\begin{array}{c}- \\
. / 19 \\
\end{array}$ & بدون همسر & تامل \\
\hline $\begin{array}{c}- \\
.|9 V| \\
* .1 \cdot r \mid\end{array}$ & $\begin{array}{l}- \\
. / 10 \\
. / 99\end{array}$ & كمتر از دييلهم سواد & تحصيلات & $\begin{array}{c}- \\
. / \cdot \Delta \Delta\end{array}$ & $\begin{array}{l}- \\
\cdot / 9 T\end{array}$ & 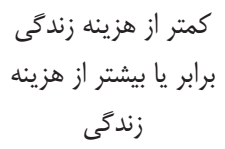 & درآمد \\
\hline
\end{tabular}

$\mathrm{P}-$ value $<\cdot / \cdot \Delta$

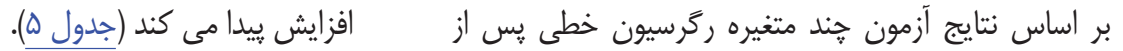
تعديل اثر متغير هاى جنس، تاهل، سن، سكونت، درآمد، تحصيلات، بيمارى مزمن، نشان داده شد كه به ازاى هر واحد افزايش در ميزان ترس از سقوط ميزان افسردى به طور معنى دارى كس//. واحد 
جدول ه: تحليل ركر سيون خطى جند متغيره عوامل موثر بر افسردگى در سالمندان ديابتيك مراجعه كننده به بيمارستان هاى شهرستان آمل سال \وسا

\begin{tabular}{|c|c|c|c|c|c|c|c|}
\hline سطح معنى دارى & ضريب بتا & \multicolumn{2}{|c|}{ متغير } & سطح معنى دارى & ضريب بتا & \multicolumn{2}{|c|}{ متغير } \\
\hline $\begin{array}{c}- \\
\cdot / V \& \Lambda\end{array}$ & $\begin{array}{c}- \\
-\cdot / \cdot r\end{array}$ & شهرى روستايى & سكونت & $\begin{array}{c}- \\
* \cdot|\cdot r|\end{array}$ & $\begin{array}{c}- \\
-. / 19\end{array}$ & زمن & جنس \\
\hline . $/ 9 \vee \mu$ & r & \multicolumn{2}{|c|}{ سن } & $*<+1 . .1$ & זr/. & \multicolumn{2}{|c|}{ ترس از سقوط } \\
\hline $\begin{array}{c}- \\
\cdot / V V V\end{array}$ & $\begin{array}{l}- \\
. / \cdot r\end{array}$ & خير & سابقه بيمارى & $\begin{array}{c}- \\
. / T N D\end{array}$ & $\begin{array}{l}- \\
\cdot 1 \cdot 1\end{array}$ & بدون همسر & تاهل \\
\hline $\begin{array}{c}- \\
. / T T \Delta \\
. / \cdot V q\end{array}$ & $\begin{array}{l}- \\
.1 \cdot 1 \\
.119\end{array}$ & كمتر از دييلهم سواد & تحصيلات & $\begin{array}{c}- \\
. / 194\end{array}$ & $\begin{array}{l}- \\
. / 1\end{array}$ & برابر يا بيشتر از هزينه زندگى هزئه & در آمد \\
\hline
\end{tabular}

$*$ P-value $<0 / 05$

مى باشد كه منبع قطعى خودكار امدى مى باشد، بنابراين ممكن است

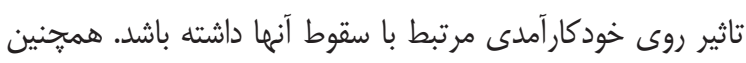

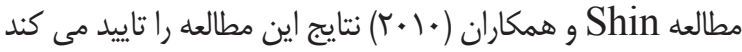

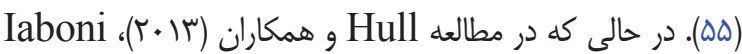
و همكاران (ها +r) ارتباطى بين ترس از سقوط و افسردى دمى ديده

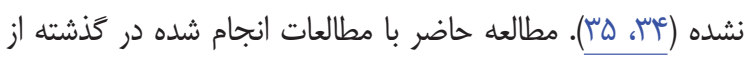
نظر همبستخى همسو است ولى در مطالعه حاضر ترس از سقوط به عنوان يك متغير مستقل در نظر كَرفته شده در حالى كه مطالعات

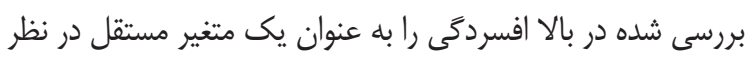

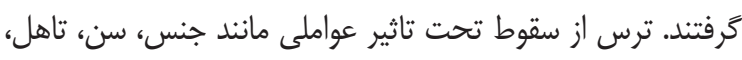
سطح تحصيلات و بيمارى مزمن قرار دارد. افزايش اين ترس منجر به بروز عوارض جبران نايذيرى براى سالمندان مى شود.. نتيجه

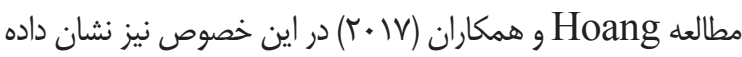
است كه ارتباط معنى دارى بين سن ، افسردگى و تاريخجه سقوط

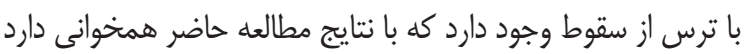

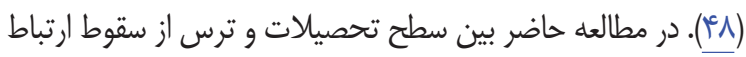
معنى دارى ديده شده است بدين صورت كه افراد با سطح تحصيلات يايين تر ترس از سقوط بيشترى داشتند كه نتيجه مطالعه Bagley

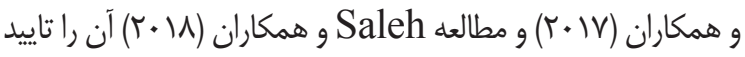

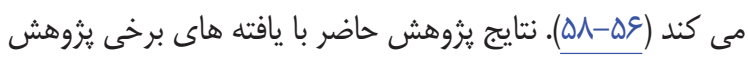

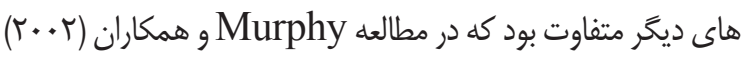

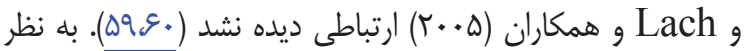
مى رسد كه تفاوت در نحوه سنجش متغير سطح تحصيلات و ترس

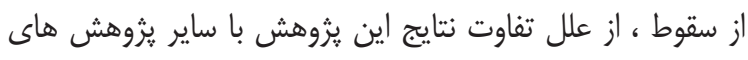

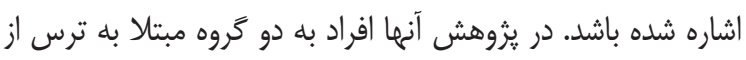
زمين خوردن و بدون ترس تقسيم شده بودند و سطوح مختلف ترس
تحقيق حاضر جهت بررسى رابطه بين ترس از سقوط و

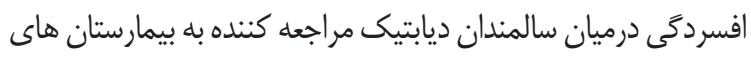
شهرستان آمل انجام شد. نتايج مطالعه نشان داد كه ارتباط مستقيه

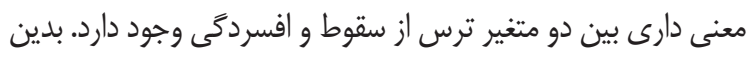

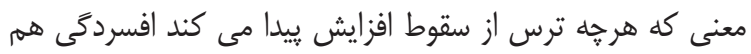

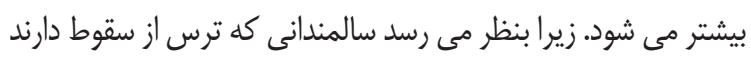

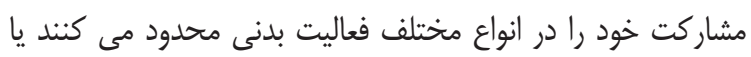

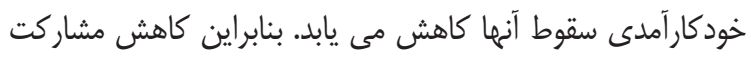

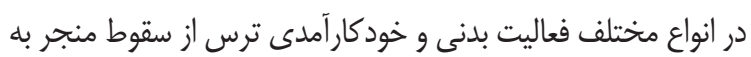
افسردى در سالمندان مى شود. در مطالعات انجام شده در كَذشته

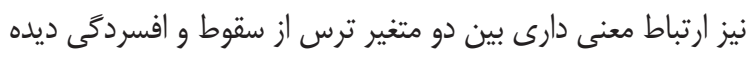

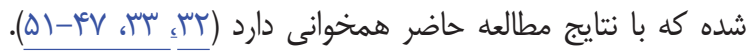

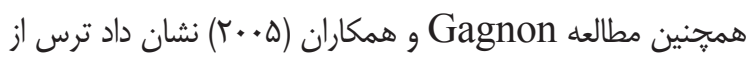

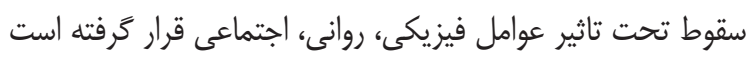

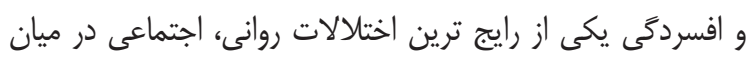
افراد سالمند است كه همسو با نتيجه مطالعه حاضر است (آهائ). زيرا

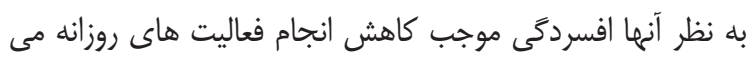

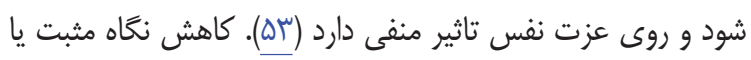

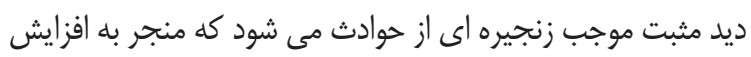
تمركز فرد روى خودش و افزايش نياز به كمك و كاهش مشار كت در فعاليت هاى لذت بخش و افز ايش غيرقابل بيش بينى ترس از سقوط

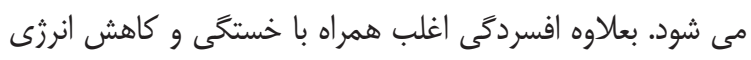
مى باشد كه مى تواند موجب دلسردى افراد از توانايى هاى جسمى خود (كاهش اعتماد به نفس) شود و بيشتر سبب ترس از سقوط شود

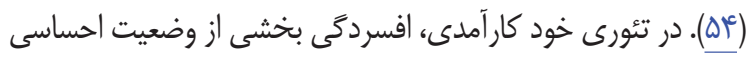


زن بيشتر از مردان بود كه با نتيجه مطالعه حاضر مطابقت دارد (YV). Clemson رسيد كه سن، جنسيت از مهمترين بيش بينى كننده هاى ترس از

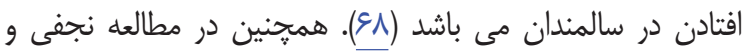

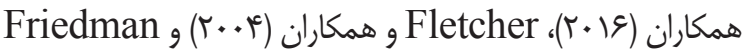

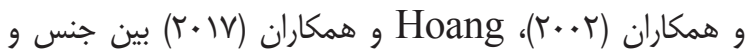
ترس از سقوط ارتباط معنى دارى ديده شده به طورى كه زنان سالمند ترس از سقوط بيشترى نسبت به مردان سالمند داشتند (ع)، مثا، هو

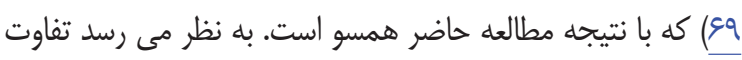
هاى آناتوميك، فيزيواوزيك و روانشناختى كه بر حسب جنسيت دئ در زنان و مردان وجود دارد مى تواند توجيه كننده رابطه ترس از افتادن با جنسيت باشد (^^). از طرف ديكر در اين مورد مى توان بيان كرد

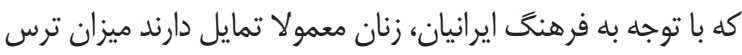

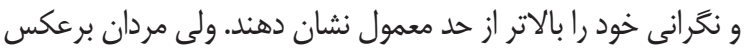
اين موضوع عمل مى كنند يعنى به كم جلوه دادن ترس و نكرانى

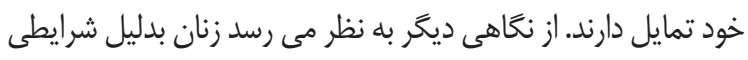

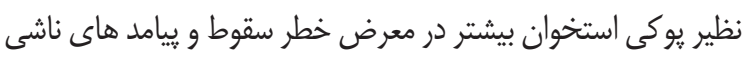

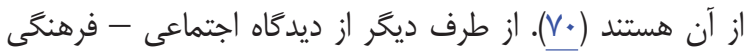
به ويزه در فرهنگ ايرانيان، مردان بايد افراد قوى باشند زيرا آنها

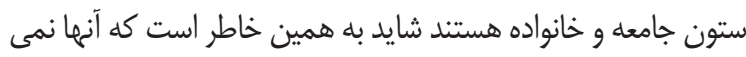
خواهند در مورد سقوط و نكرانى هايشان صحبت كنند. در مطالعه

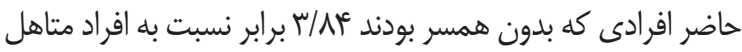
ترس از سقوط بيشترى داشند. كه در اين رابطه در مطالعه Eunmi و همكاران (Vh

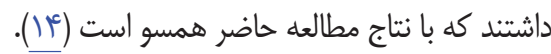
در مطالعه حاضر بين ترس از سقوط و بيمارى مزمن ارتباط معنى دارى ديده شده به اين صورت كه سالمندان با بيمارى مزمن ترس از سقوط بيشترى داشتند كه با نتايج مطالعات انجام شده در دران كذشته همسو است ("(1). زيرا به نظر مى رسد سالمندان با بيمارى

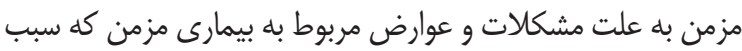
افت عملكر د اين بيماران مى شود بيشتر در معرض خطر سقوط باشند و به همين علت ميزان ترس از سقوط بيشترى دارند.

\section{نتيجه تَيرى نهائى}

از آنجايى كه نتايج يزوهش حاضرى آشكار ساخت ترس از سقوط مى تواند منجر به افسردى سالمندان شود. مداخلات متعددى ترى با هدف جلوَّيرى از ترس از سقوط در سالمندان انجام شده است مانند برنامه هاى ورزشى مختلف نظير آموزش قدرت، تعادل، استقامت،
بررسى نشده بود و از طرفى ديخر در يثوهش آنها سطح تحصيلات به جهار زير كروه و دو زير كروه تقسيم شده است ، شايد همين مسئله دليل تفاوت در نتايج مطالعات باشد.

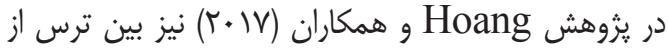

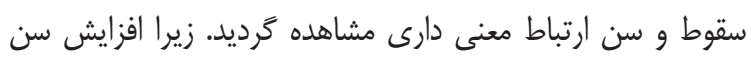

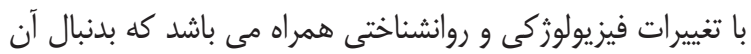
افزايش موارد سقوط و همجنين ترس از سقوط در سالمندان مشاهده

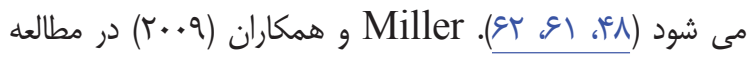
اى به اين نتيجه رسيدند كه با افزايش سن ترس از سقوط هم افزايش ميابد، زيرا سالمندان به علت تغييرات مرتبط با سن، از جمله مكانيزم هاى هموستاتيك عصبى-عضلانى و قلبى، ضعف فيزيكى،

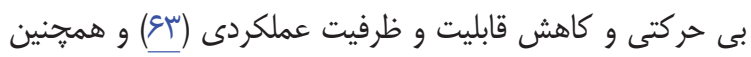

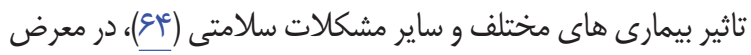

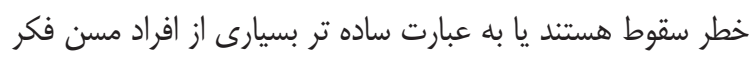

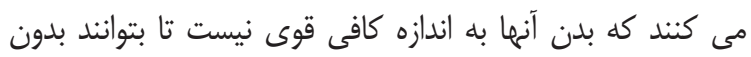
ريسك كمترى از سقوط فعاليت داشته باشند. آنها همجنين ممكن

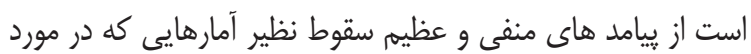
تلفات شديد سقوط سالمندان و مركَ و مير هاى ناشى از سقوط وجود

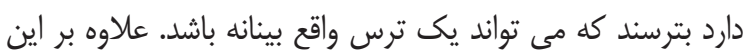

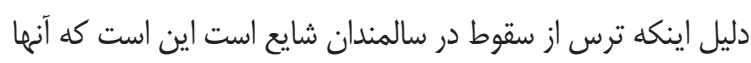
تمايل به صحبت و بزر كنمايى كردن نكرانى در مورد سلامت خود و ترس از وقايع و شرايط خاص به خصوص سقوط دارند (^)َ). بنابراين

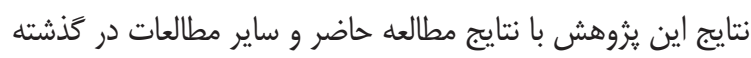

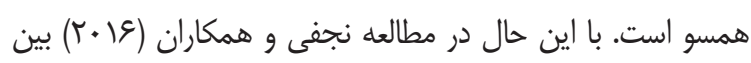
سن و ترس از سقوط تفاوت معنى دارى مشاهده نشد (هQ؟). تفاوت

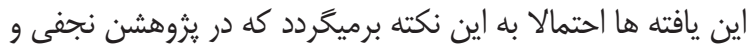

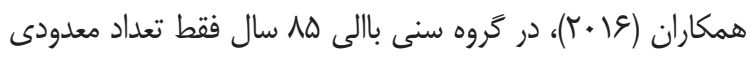

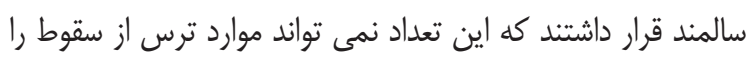
در اين گَروه سنى به درستى نشان دهد. ميانخين ترس از سقوط

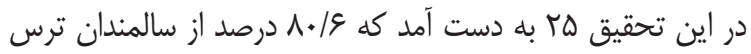

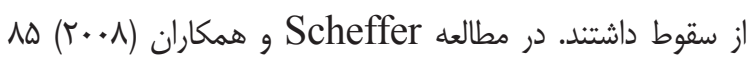
درصد سالمندان ساكن جامعل ترس از سقوط داشتند (T). مطالعه Lopes

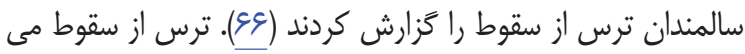

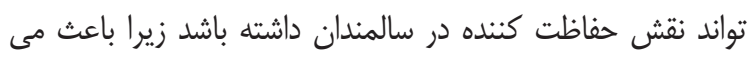

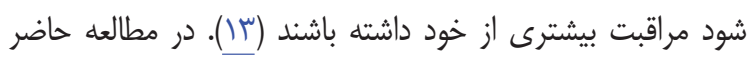

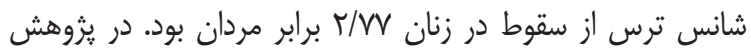
Arfken 


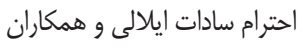

$$
\begin{aligned}
& \text { سقوط سالمندان ضرورى است. }
\end{aligned}
$$

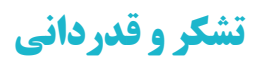

$$
\begin{aligned}
& \text { اين مقاله مستخرج از پايان نامه كارشناسى ارشد در رشته }
\end{aligned}
$$

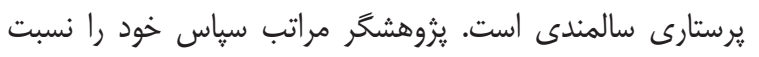

$$
\begin{aligned}
& \text { مسئولين محترم بيمارستان هاى شهرستان آمل و كار كنان محترم آن }
\end{aligned}
$$

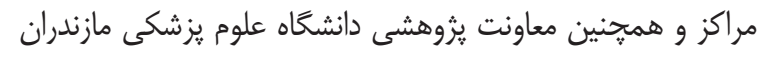

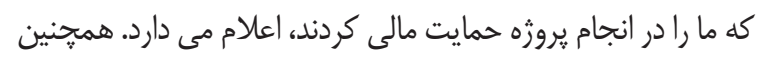

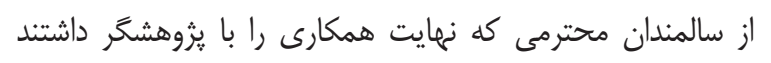

$$
\begin{aligned}
& \text { نهايت تشكر و قدردانى مى كَردد. }
\end{aligned}
$$

\section{References}

1. Hemmati Maslakpak M HL, Khalkhali HR. The effect of implementing orem's self-care model on the self-esteem of elderlies resident of nursing home in Urmia. Medical Surgical Nursing Journal, 2012; 1(1):18-23. (persian).

2. Nanbakhsh F MH AA, Hajshafiha M, Broomand F, Bahadori F, MohamadloS. The effect of health education on elderly weomen life quality. Faculty of Allied Health Sciences, Tehran University of Medical Sciences. 2011; 5 (1): 42-57. (persian).

3. Statistical center of Iran.Population and Housing census. Available from: http://amarorgir/english/ Census.2016. (persian).

4. Luukinen H KK, Hiltunen L, Kivelä S-L. Incidence rate of falls in an aged population in northern Finland. J Clin Epidemiol 1994; 47 (8):843-50.

5. Orces CH. Prevalence and determinants of fallrelated injuries among older adults in Ecuador. Curr Gerontol Geriatrics Res 2014; 2014: 1-7.

6. Davoodi F, Etemad K, Tanjani PT, Khodakarim S. The relationship between depression and cognitive impairment with falls leading to fractures in elderly. Safety Promotion and Injury Prevention. 2016; 4 (2):75-82. (persian).

7. Orces CH. Prevalence and determinants of fallrelated injuries among older adults in Ecuador. Current gerontology and geriatrics research. 2014; 2014.

8. Gilasi H SH, Yazdani S, Taheri TP. Fall-Related Injuries in Older People in Kashan. Journal Of Paramedical Science and Rehabilitation (JPSR). 2015; 4 (3):74-82. (persian)

9. Torkaman Gholami J MSF, Norouzi K, Reza

$$
\begin{aligned}
& \text { تحرك و ورزش تاى هى ثابت كرده اند كه در كاهش ترس از سقوط }
\end{aligned}
$$

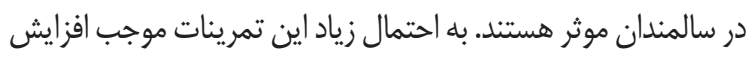

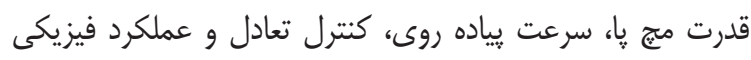

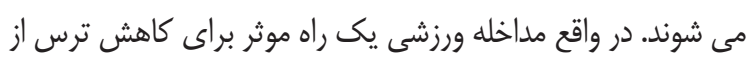

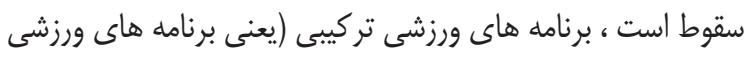

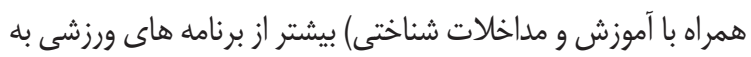

$$
\begin{aligned}
& \text { تنهايى موثر خواهند بود. بطور مثال برنامه هاى ورزشى كه در خانه }
\end{aligned}
$$

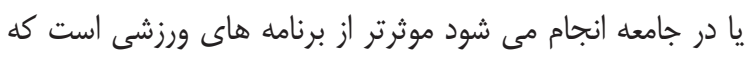

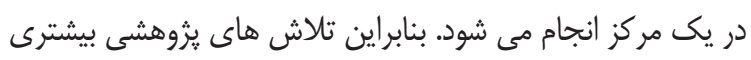

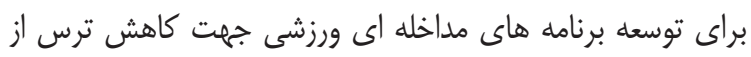

soltani P. The Relationship between Fear of falling and Activity Limitations among Seniors of Ghaem Shahr City in 2013. IJRN. 2015; 2 (1): 45-52. (persian)

10. Nejati V, Ashayeri H. Evaluation of Relationship Between Depression and Cognitive Impairment in Elderly. Iranian Journal of Ageing. 2007; 1 (2): 112-8. (persian).

11. Desforges JF TM, Speechley M. Prevention of falls among the elderly. New England Journal of Medicine. 1989; 320 (16): 1055-9.

12. Lachman ME HJ, Tennstedt S, Jette A, Assmann S, Peterson EW. Fear of falling and activity restriction: the survey of activities and fear of falling in the elderly (SAFE). The Journals of Gerontology Series B: Psychological Sciences and Social Sciences., 1998; 53 (1):43-50.

13. Borhaninejad V, Rashedi V, Tabe R, Delbari A, Ghasemzadeh H. Relationship between fear of falling and physical activity in older adults. medical journal of mashhad university of medical sciences. 2015;58(8):446-52. (persian)

14. Oh E, Hong G-RS, Lee S, Han S. Fear of falling and its predictors among community-living older adults in Korea. Aging \& mental health. 2017; 21 (4): 369-78.

15. Martin FC, Hart D, Spector T, Doyle DV, Harari D. Fear of falling limiting activity in young-old women is associated with reduced functional mobility rather than psychological factors. Age and Ageing. 2005; 34 (3): 281-7.

16. Fletcher PC, Hirdes JP. Restriction in activity associated with fear of falling among communitybased seniors using home care services. Age and Ageing. 2004; 33 (3): 273-9. 
17. Brouwer B, Musselman K, Culham E. Physical function and health status among seniors with and without a fear of falling. Gerontology. 2004; 50 (3): 135-41.

18. Cumming RG, Salkeld G, Thomas M, Szonyi G. Prospective study of the impact of fear of falling on activities of daily living, SF-36 scores, and nursing home admission. The Journals of Gerontology Series A: Biological Sciences and Medical Sciences. 2000; 55 (5): 299-305.

19. Li F HP, Fisher KJ, McAuley E, Chaumeton N, Eckstrom E, Wilson NL. Tai Chi and fall reductions in older adults: a randomized controlled trial. The Journals of Gerontology Series A: Biological Sciences and Medical Sciences. 2005 Feb 1;60 (2):187-94.

20. Soleimani MA BF, Negarandeh R. Exploraing of challenges of self-care in people with Parkinson's disease: Resulting from qualitative research study Iranian Journal of Gerontology. 2016; 1 (1): 78-63. (persian).

21. Kesavadev J, Short K, Nair KS. Diabetes in old age: an emerging epidemic. Journal-Association Of physicians of India. 2003; 51: 1083-94.

22. Beiranvand S, Fayazi S, Asadizaker M, Latifi SM. The prevalence of chronic diseases in the elderly fall andits relationship with the city of Khorramabad. Journal of Clinical Nursing and Midwifery. J Clin Nurs Midwifery. 2014; 3 (2): 57-66. (persian).

23. Salarvand S, Birjandi M, Shamshiry M. The prevalence of chronic diseases in the elderly fall andits relationship with the city of Khorramabad. Knowledge Horizon, Faculty of Medical Sciences and Health Services Gonabad. 200813 (4): 59-65. (persian).

24. Allet L, Armand S, Golay A, Monnin D, De Bie R, De Bruin E. Gait characteristics of diabetic patients: a systematic review. Diabetes/ metabolism research and reviews. 2008; 24 (3): 173-91.

25. De Mettelinge TR, Cambier D, Calders P, Van Den Noortgate N, Delbaere K. Understanding the relationship between type 2 diabetes mellitus and falls in older adults: a prospective cohort study. PloS one. 2013; 8 (6):e67055.

26. Kelly C, Fleischer A, Yalla S, Grewal GS, Albright R, Berns D, et al. Fear of falling is prevalent in older adults with diabetes mellitus but is unrelated to level of neuropathy. Journal of the American Podiatric Medical Association. 2013;103 (6): 480-8.

27. Sankhe P, Ganvir S. Association between Physical Functioning and Fear of Falling with Balance in Elderly Diabetic Individuals. Journal of Physiotherapy \& Physical Rehabilitation. 2017; 2 (3): 148.

28. Bruce D, Hunter M, Peters K, Davis T, Davis W. Fear of falling is common in patients with type 2 diabetes and is associated with increased risk of falls. Age and ageing. 2015; 44 (4): 687-90.

29. Sadock B, Sadock V, Kluwer W. 10th ed. Synopsis of psychiatry: Behavioral science and clinical psychiatry. New york:Lippincott Williams \& Wilkins; 2011:157 (11): 1145_51.

30. Sadeghie Ahari S, Arshi S, Iranparvar M, Amani F, Siahpoosh H. The effect of complications of type II diabetes on patients' quality of life. Journal of Ardabil University of medical sciences. 2008; 8 (4): 394-402. (persian).

31. Mousavi SA, Aghayan S, Razavianzadeh N, Nourouzi N, Khosravi A. Depression and General health status in type ii diabetic patients . 2008. (persian).

32. Mishra N, Mishra AK, Bidija M. A study on correlation between depression, fear of fall and quality of life in elderly individuals. International Journal of Research in Medical Sciences. 2017; 5 (4): 1456-60.

33. Painter JA, Allison L, Dhingra P, Daughtery J, Cogdill K, Trujillo LG. Fear of falling and its relationship with anxiety, depression, and activity engagement among community-dwelling older adults. American Journal of Occupational Therapy. 2012; 66 (2): 169-76.

34. Hull SL, Kneebone II, Farquharson L. Anxiety, depression, and fall-related psychological concerns in community-dwelling older people. The American Journal of Geriatric Psychiatry. 2013; 21 (12):1287-91.

35. Iaboni A, Banez C, Lam R, Jones SA, Maki BE, Liu BA, et al. Depression and outcome of fear of falling in a falls prevention program. The American Journal of Geriatric Psychiatry. 2015; 23 (10):1088-97.

36. Mirzaei M, Daryafti H, Fallahzadeh H, Azizi B. Evaluation of Depression, Anxiety and Stress in Diabetic and Non-Diabetic Patients. SSU_ 
Journals. 2016; 24 (5): 387-97. (persian).

37. Ahmadi A, Hasanzadeh J, Rahimi M, Lashkari

L. Effective factors in the quality of life of patients with type 2 diabetes in Chaharmahal \& Bakhteyari province. Journal of North Khorasan University of Medical Sciences. 2011; 3 (1):713. (persian).

38. Nicholson Jr NR. The relationship between injurious falls, fear of falling, social isolation and depression. 2005.

39. Yardley L, Beyer N, Hauer K, Kempen G, Piot-Ziegler C, Todd C. Development and initial validation of the Falls Efficacy ScaleInternational (FES-I). Age and ageing. 2005; 34 (6):614-9.

40. Khajavi D, Farokhi A, Jaberi Moghadam AA, Kazemnejad A. The impact of a training intervention program on fall-related psychological factors among male older adults in Arak. Iranian Journal of Ageing. 2014; 9 (1):329. (persian).

41. Malakouti K, Fathollahi P, Mirabzadeh A, Salavati M, Kahani S. Validation of Geriatric Depression Scale (GDS-15) in Iran. Pejouhesh dar Pezeshki (Research in Medicine). 2006; 30 (4): 361-9. (persian).

42. Katz S, Ford AB, Moskowitz RW, Jackson BA, Jaffe MW. Studies of illness in the aged: the index of ADL: a standardized measure of biological and psychosocial function. Jama. 1963; 185 (12): 914-9.

43. Habibi Sola A, Nikpoor S, Rezaei M, Haghani H. Health Promotion Behaviours and Level of Activities of Daily Living and Instrumental Activities of Daily Living Among Elderly People in West Region of Tehran: A Cross-Sectional Survey. Iranian Journal of Ageing. 2007; 2 (3): 331-9. (persian).

44. McDowell I. Measuring health: a guide to rating scales and questionnaires: Oxford university press; 2006.

45. Hodkinson H. Evaluation of a mental test score for assessment of mental impairment in the elderly. Age and ageing. 1972; 1 (4):233-8.

46. Foroughan M, Wahlund LO, Jafari Z, Rahgozar M, Farahani IG, Rashedi V. Validity and reliability of Abbreviated Mental Test Score (AMTS) among older Iranian. Psychogeriatrics. 2017; 17 (6): 460-5. (persian).
47. Chou K-L, Yeung F, Wong E. Fear of falling and depressive symptoms in Chinese elderly living in nursing homes: Fall efficacy and activity level as mediator or moderator? Aging \& mental health. 2005; 9 (3): 255-61.

48. Hoang OTT, Jullamate P, Piphatvanitcha N, Rosenberg E. Factors related to fear of falling among community-dwelling older adults. Journal of clinical nursing. 2017; 26 (1-2): 68-76..

49. Malini FM, Lourenço RA, Lopes CS. Prevalence of fear of falling in older adults, and its associations with clinical, functional and psychosocial factors: The Frailty in Brazilian Older People-Rio de Janeiro Study. Geriatrics \& gerontology international. 2016; 16 (3): 336-44.

50. Oh-Park M, Xue X, Holtzer R, Verghese J. Transient versus persistent fear of falling in community-dwelling older adults: incidence and risk factors. Journal of the American Geriatrics Society. 2011;59 (7): 1225-31.

51. van Haastregt JC, Zijlstra GR, van Rossum E, van Eijk JTM, Kempen GI. Feelings of anxiety and symptoms of depression in communityliving older persons who avoid activity for fear of falling. The American Journal of Geriatric Psychiatry. 2008;16 (3): 186-93.

52. Gagnon N, Flint AJ, Naglie G, Devins GM. Affective correlates of fear of falling in elderly persons. The American journal of geriatric psychiatry. 2005; 13 (1): 7-14.

53. Legters K. Fear of falling. Physical therapy. 2002; 82 (3): 264-72.

54. 54. Burker EJ, Wong H, Sloane PD, Mattingly D, Preisser J, Mitchell CM. Predictors of fear of falling in dizzy and nondizzy elderly. Psychology and aging. 1995; 10 (1): 104.

55. Shin KR, Kang Y, Kim MY, Jung D, Kim JS, Hong CM, et al. Impact of depression and activities of daily living on the fear of falling in Korean community-dwelling elderly. Nursing \& health sciences. 2010; 12 (4): 493-8.

56. Bagley J. Predictors of Fear of Falling and Activity Avoidance in Community-Dwelling Older Adults: University of Hawai'i at Manoa; 2017.

57. Chu C-L, Liang C-K, Chow PC, Lin Y-T, Tang K-Y, Chou M-Y, et al. Fear of falling (FF): Psychosocial and physical factors among institutionalized older Chinese men in Taiwan. 
Archives of gerontology and geriatrics. 2011; 53 (2):232-6.

58. Saleh NMH, Ibrahim HS, Mohamed HNAE-A, El-Gilany A-H. Predictors of Fear of Falling among Community Dwelling Older Adults in Mansoura City, Egypt. International journal of Nursing Didactics. 2018; 8 (08): 63-71.

59. Lach HW. Incidence and risk factors for developing fear of falling in older adults. Public health nursing. 2005; 22 (1):45-52.

60. Murphy SL, Williams CS, Gill TM. Characteristics associated with fear of falling and activity restriction in community-living older persons. Journal of the american geriatrics society. 2002; 50 (3): 516-20.

61. Kumar A, Carpenter H, Morris R, Iliffe S, Kendrick D. Which factors are associated with fear of falling in community-dwelling older people? Age and ageing. 2014; 43 (1):76-84.

62. Scheffer AC, Schuurmans MJ, Van Dijk N, Van Der Hooft T, De Rooij SE. Fear of falling: measurement strategy, prevalence, risk factors and consequences among older persons. Age and ageing. 2008; 37 (1):19-24.

63. Miller CA. Nursing for wellness in older adults: Lippincott Williams \& Wilkins; 2009.

64. World Health Organization (2007) WHO Global Report on Falls Prevention in Older Age. World Health Organization G, Switzerland.

65. Najafi Ghezlcheh T, Ariapour S, Jafari Oori M. Epidemiology and relationship of fall and fear of falling in the elderly residing at Kamrani nursing home, Tehran, Iran. Iranian Journal of Ageing. 2016;10 (4):152-61. (persian).

66. Lopes K, Costa D, Santos L, Castro D, Bastone A. Prevalence of fear of falling among a population of older adults and its correlation with mobility, dynamic balance, risk and history of falls. Brazilian Journal of Physical Therapy. 2009;13 (3): 223-9.

67. Arfken CL, Lach HW, Birge SJ, Miller JP. The prevalence and correlates of fear of falling in elderly persons living in the community. American journal of public health. 1994; 84 (4): 565-70.

68. Clemson L, Kendig H, Mackenzie L, Browning C. Predictors of injurious falls and fear of falling differ: an 11-year longitudinal study of incident events in older people. Journal of aging and health. 2015; 27 (2): 239-56.

69. Friedman SM, Munoz B, West SK, Rubin GS, Fried LP. Falls and fear of falling: which comes first? A longitudinal prediction model suggests strategies for primary and secondary prevention. Journal of the American Geriatrics Society. 2002; 50 (8):1329-35.

70. Stevens JA, Sogolow ED. Gender differences for non-fatal unintentional fall related injuries among older adults. Injury prevention. 2005; 11 (2): 115-9. 